\title{
TITLE: DIMENSION IND ENTROPY FOR QUASIPERIODIC AND CHAOTIC CONVECTION
}

AUTHOm(S) H. Haucke, K. E. Ecke, and J. C. Wheatley

submitted to Proceedings of the International Conference on Dimensions and Entropies in Chaotic Systems, September 11-16, 1985 Pecos River, NM

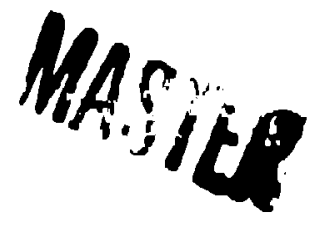

\section{DISCLAIMER}

This report was prepared as an accuunt of :zork aponeored ty an aconcy of the Uniled States Government. Nelther the United States Government nor any egency thereof, nor any of their employoes, makes any warranty, expreas or impiled, or asumes any legal lisbility or responai. billity for the accuracy, completeneas, or usefulness of any information, apparalus, product, or process disclosed, or ropresonts that its use would not infringe privately owned riphis. Reference herein to any speciffic commercial product, proces, or servico by trade name, trademark. manufacturer, or otherwise does not necesuarily conatitute or imply tts endorsement, recom. mendation, or favoring by the Unitod Stutea Government or any agency thereof. The viowe and opinione of authore expreased herein do not necesurily atale or reflect thone of the United Siatea Govornment or any agency thereor. 
Dimension and Entropy for Quasiperiodic and Chaotic Convec:ion

H. Haucke, R. E. Ecke and J. C. Wheatley

Los Alamos Mat'onal Laboratory

Los Alamos. New Mextco 87545

\section{Abstract}

High quality experimental data have been taken on a convection cell containing a dilute 3 He-4ke solution. We discuss some problems with the determina:ton of diminsion and entropy for experimental data, and compare the results to detalled poincart sections. At the chaotic transition. we show the behavior of diension and entropy as a function of Rayleigh number.

Rayleigh-Benard convection has been perhaps the most intensively studied nonlinear experimental system. Oimension and entropy calculations on convection data have been carried out by MALRAISON, ATTEM, BERGE and DUBOIS [1] as well as GIGLIO et. a 1. [2]. Work done on dimens lonality of attractors for other hydrodynamic systems includes that of BRANOSTXTER, et. al. [3] for Couette-Taylor flow and EUCKENHEIMER and BUZYNA [4] for geostrophic flow. Theoretical and practical aspects of dimension and entropy measurement are discussed in a recent revied article by ECKMANM and RUELLE [5] We report here on systematic observations of convection in a He-superflutd bie solution, In wich we have achieved extremily low levels of noise and drift. Measurements were made over the transition region for the breakdow of a two-torus into a chaotic attractor. Calculations of diension and entrcpy as a function of an external stress paraneter are presented.

The flutd used in this work is a dilute solution of $1.46 \%$ 3e in superfluid He. One can treat this solution as a one-component fluid and derive $a$ Rayleigh number $R$, analagous to the Rayleigh number ased as the stress paraneter for convection in ordinary fluids. and proportional to the top-botton temperature difference. A second dimensionless parameter. the Prandt l umber. Is requirad to fully characterize the system in the one-component Boussinejq approximation. Theoretical [6] and experimental $[7,8]$ Justification for the one-component treataent of these soluticns, and defintitions of the appropriate Prandtl and Rayleigh numbers may be found in previcus publications [7].

In this work we are using a rectangular geonetry with height $d=0.80 \mathrm{~cm}$, length $2.0 \mathrm{~d}$. and width $1.4 \mathrm{~d}$. The sidewalls are themaliy insulating relative to the flutd. whereas the top and botton boundaries are thenwally conducting. In operation. the bottom boundary is mintained at a fixed temperature by feedback control. A fixed heat current is aDDlied to the top boundary. Detalls of cell construction and op iration can be found elsewhere [7].

The tire serles discussed below are all derlved from a single differential themocouple sensor. One end of the thernocouple is atteched to the copper plate forming the upper boundary of the cell; the other to a smill, cylindrical, thermally isolated copper plug inserted into the center of the ubDe: plate. The sensor is sensitive to local temperature gradients but not to fluctuations in the mean cell temperature. Thts is one reason for our very low notse level.

With a smil heat flow through the cell, the fluid is motionless and conducts heat diffusively. Increasing the heat flow increases the temperature difference betieen the top and $l$ ttmm boundaries and thus the Rayleigh number. When the critical Rayleigh number $R_{r}$ is reached the fluld begins to convert. Further increasing the Raylelgh number excites first one osclilutory instability and then second, as shom in fig. 1. In the two-frequency region we observe node-locking. As the Rayletigh number is increased through this region. a large discontinuous change in both oscillatory 
frequericies is observed and the shape of the attractor changes drastically. We will concentrate henceforth on the region above this discontinuity and below the chaotic onset.

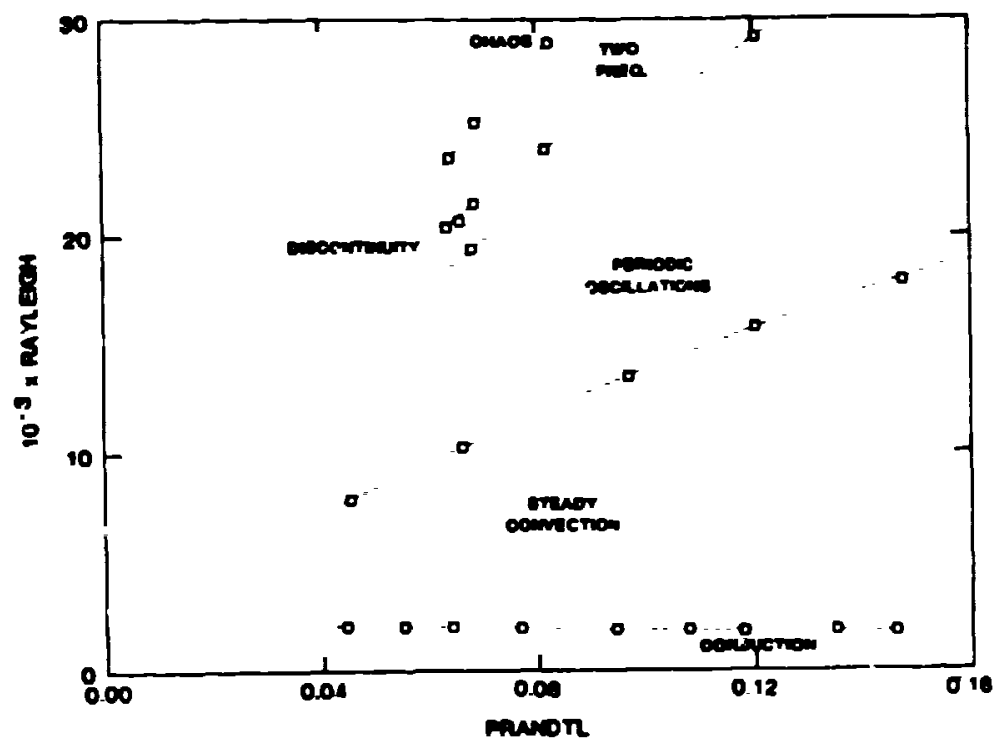

Fig. 1 Phase diagram of transitions on the Rayleigh-Prandt 1 number plane

We define winding number $W=f_{2} / f_{1}$. were $f_{1}-0.7 \mathrm{~Hz}$ and $f_{2}-0.1 \mathrm{~Hz}$ are the fundamental frequencles of the first and second instabilities seen with increasing $R$. Figure 2 shows a plot of $W$ versus nomalized Rayleigh number. Many flat steps are visible. At the upper right the system has become chaotic. While we find that

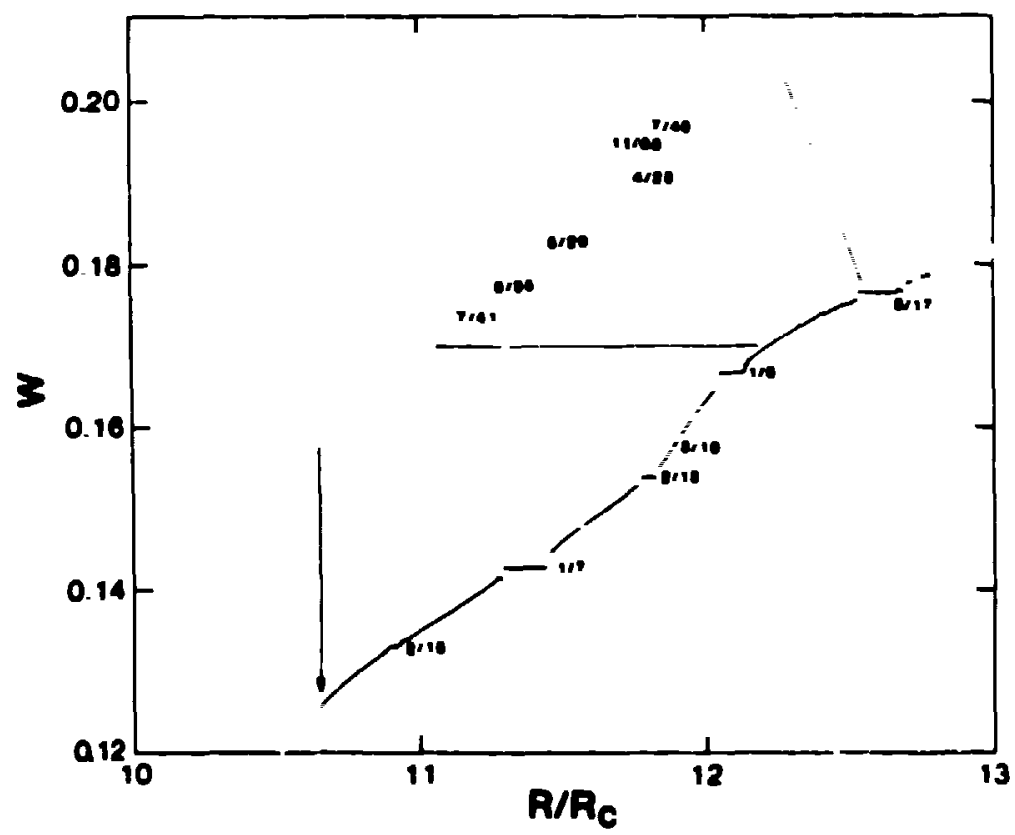

F19. 2. A plot of winding number as a function of norms lized Rayietgh number showing a number of mode-locking steps. $R_{c}=2011$ 
the chaotic transition is "continuous" or gradual and thus hard to identify piecisely. on the scale of Figs. I or 2 this is not a problem. For each point in Fig. 2 the irequencles $f_{1}$ and $f_{2}$ are deternined by acquir'ng a time ser!es, generisting the power spectrum, and fitting peak frequencies. A more detalled discussion of the node-locking will appear elsewhere [9] tut a brief overview is given here. As an example of simple quasiperlodic data. we show in Fig. 3 the attractor for a state wall below the chaotic onset. This projection is produced using the usual "dplay coordinate" method [10]. The delay time used in constructing the phase space we denote by $T: T-5.81$ seconss. for Figs. 3-5. Despite its rather contorted appearance, this is nice two-torus. By making a suitable cut (lllustrated by the shaded plane in fig. 3) w produce the simple Poincare section of fig. 4. Using the parametrization shown yields the return map. Fig. 5 .

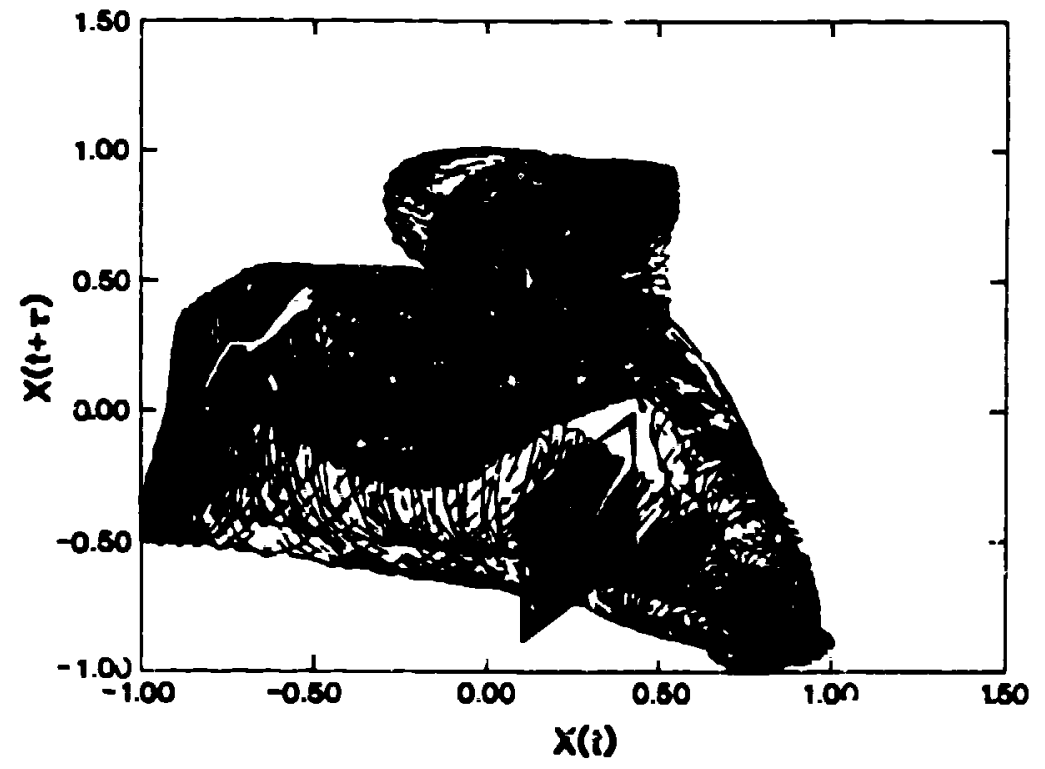

Fig. 3. Delay coordinates are used to generate a phase space. This shows a twodimensional projection of a quefperlodic ateractor and the cutting surface used to produce Fig. 4

As $R / R_{C}$ is increased the system becomes increasingly complex and 1-0 mapping no longer is adequate to descrite the syst $=2$. Hysteres is and Hopf bifurcations from locked states are observed [9]. and indicate 2-0 a noing is nesessary to characterize the state. Continuing upwerds in $R / R_{C}$, we observe chantic states having broadband spectral noise and Polncare sactions with no apparent struciure. We have used several cimension algoriemns, describad below, to characterize the states near the chootic onset.

In 11 our dimenston work we rely on the standard "delay coordinate" inthod [10] far generating. phase space. In all of wat follows wh he used 33,000 point time series 38.5 minutes in length. We heve epplied three different diension algorithms to our data. In all of these, we flist rancomly select a subset of points on the attrastor as our reference doints (enough for good statistics but not excessive computation time). Our most extensively used mthod is due to chassaERo[p ot. 4 . [11]. In this case. or each reference point the distance to all other points is calculaced. These separations are then accumulated fer all the reference points and the number of seosrations greater than or equal to $c$. called $C(c)$. Is calculated. A second a lgorlthe follows TERMOwIa [12]. Giden some number of points $n$, $R(n)$ is the radius of the sanilest bell around e reference point that contains $n$ points. $R(n)$ is 


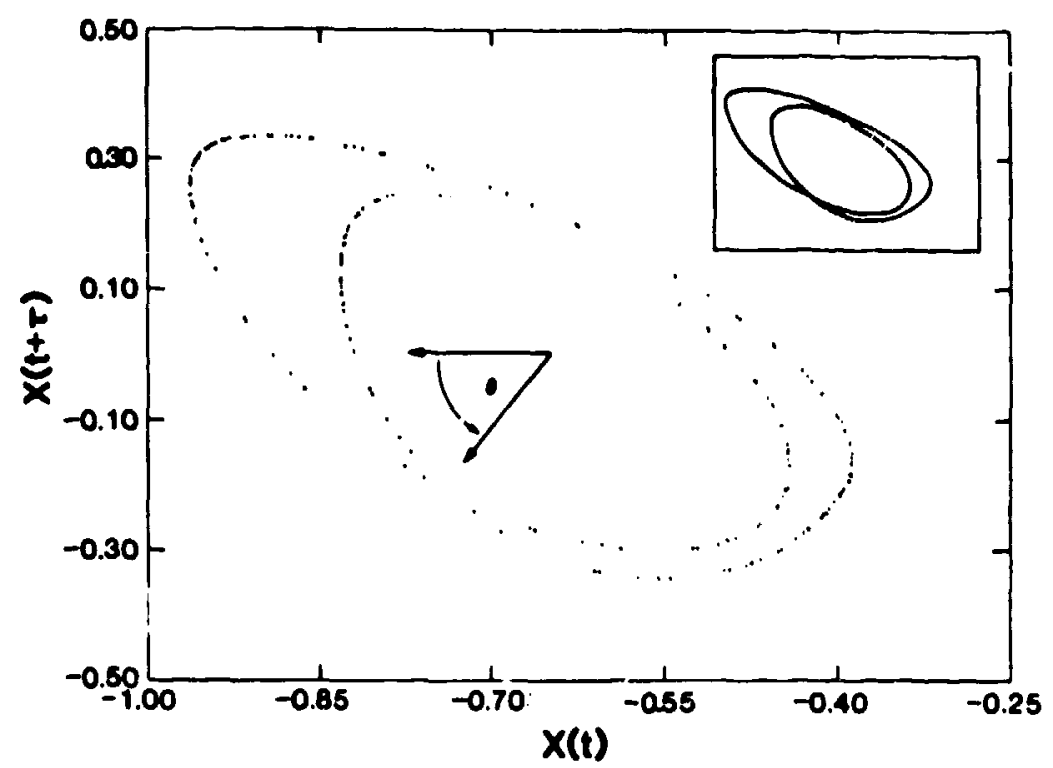

F1g. 4. This Polncare section lllustrates the simple behavior present well below the chaotic onset

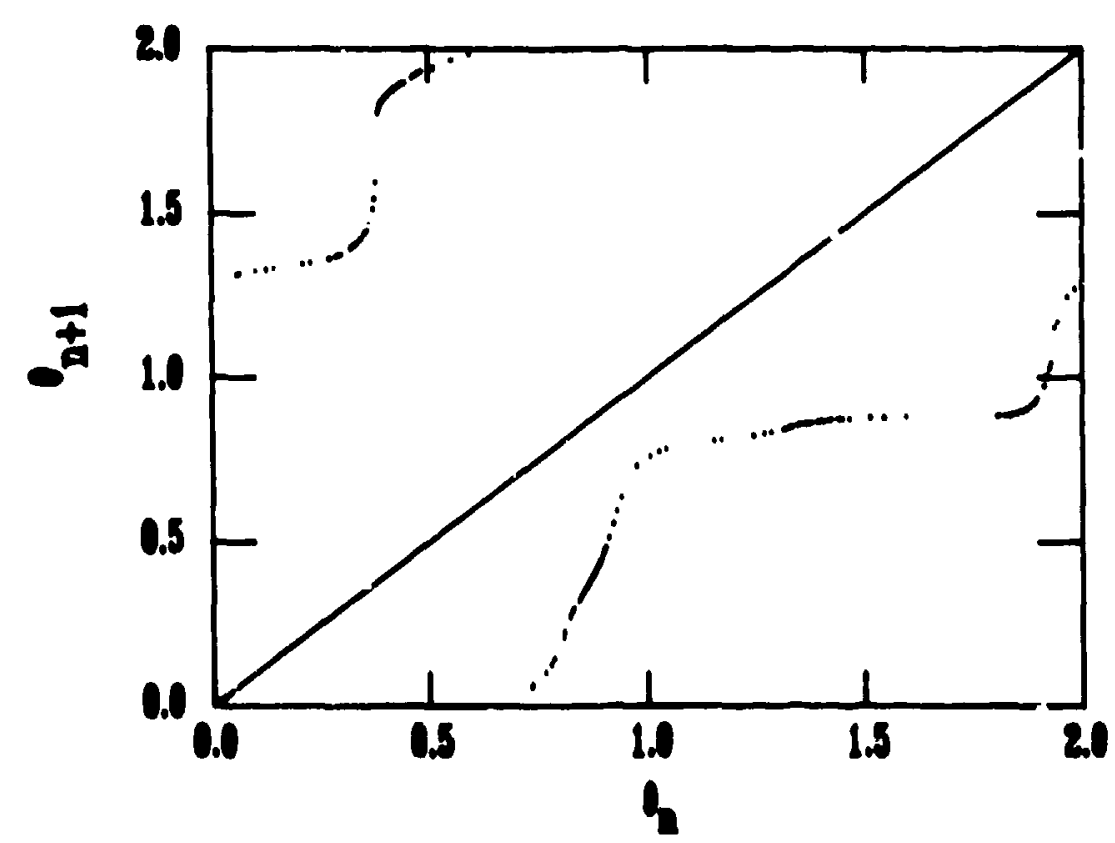

Fig 5. A return map corresponding to the date in Fig. 4

determined for each reference point and then averaged. It is the averaping process that distingulshes this agorlthm from Grassberger's. Finaliy, a can calculate the number of points $N$ inside a ball of radlus c clrcumscrlbed about reference point and average $\ln (N(c))$ over the chosen set of reference points. Tl. is is knowl bs the "Dointwise" dimension. Additionally, three definitions of distance nay be used: the max norm, defined as the lergest of all the coordinate difference:; the mod norm, defined is the sum of the absolute velues of each coordinate difference; and. finally. 
the standard Euclidian distance, defined as the square-root of the sum of the squares of the coordinate differences.

We explored the variation of dimension using different methods of calculating point separations, and using the different cimension algorithms as described above. We found no systematic variation of dimension with the different nom definitions. However, a systenatic variation wa found in a comparison of the three different algorithns. The Grassberger-Proccacia algorithm ylelded dimension values which were usually 10 to $15 \%$ below the values obtained using the other two algorithns. The parameters used in the algorfthms were a delay of $r=1.05$ seconds, $i v e$ hundred reference points and embedding dimensions ranging from 3 to 10 . Thi: convergence with increasing embedding dimension was approximately $\pm 5 \%$ for all three algorithms. None of the algorithas proved scperior in the sen e of more apparent scaling regions or less scatter in the extracted dimension. Therefors, we recomend the Grassberger-proccacle a gorithm with the max norm for ease and speeil of computation.

As noted above we used a randomly selected subset of reference points to calculate the dimensien. We found that there was appreclable variation in the dimension when this subset was too small and that the variance in the average dimension decreased as the sauare ruot of $\lambda_{\text {ref }}$, the number of reference points. In Fig. 6 , the variation of dimension with the cholce of a particular set of reference doints and the nimber in that set is show. In both cases. 7 seconds and max nom distances were used in computation of the Grassberger-Proccacia algorithm for an embedding dimension of five. For each histogram 25 different sets of reference points were used. The left pair of nistograns are for a simple quasiperiodic state wich yields an avereje dimension of 2.25 . The variance in the average dimension is 0.15 und 0.05 fa: Nref $=10$ and 100 , respectively. For a chaotic state (the right pair of histograms). the variance is 0.23 and 0.07 for $N_{r e f}=10$ and 100 . Aithough the absolute variance is greater for the chaotic data. the fractional effect is about the same, 78 and $2 x$ for $N_{\text {ref }}=10$ and 100 respectively.

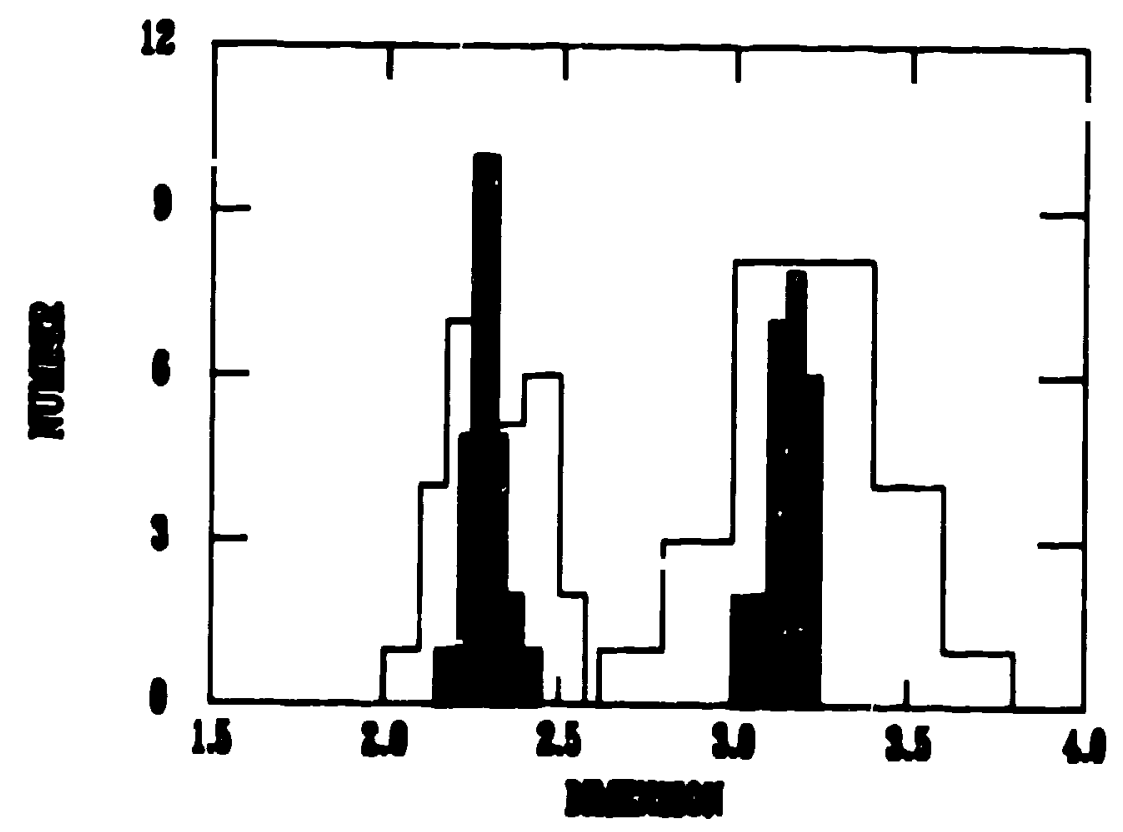

F19. 6. Variation of distribution of dimensions with size of reference subset for simple quasloeriodic data (left) and chaotic data (r'ght). Nref - 10 (shaded). Nref - 100 (outined). Twenty-five different subsets were used 
The variation of the dimension with the value of the delay used in the phase space reconstruction was also investigated. Aga in we used the Grassberger-Proccacia algorithm with max norm distance, an embedding dimension of five, and 200 reference points, and fit over a fixed region of $C(c)$. As seen in Fig. 7, there was only slight varlation for the simple quasiperiodic state but a substantial increase in the dimension of the chaotic state for $T>7$ seconds. In addition there was dip at $>>1$ second in both data sets corresponding to a delay time commensurate with the shorter period of $\sim 1.2$ seconds. Peaks in the dimension for the chaotic data at $1=7.5$ seconds and 15 seconds may be due to comensuration with the long period of -8 sec. He would in general expect that picking a value of the delay close to a osclllacion period would reduce rather than increase the dimension. However, the general trend of increasing dimension after some finite delay is reached is typical for states having positive entropy. Positive entropy requires that the attractor has some finite width to its probability density along the dth coordinate even when $d$ is much greater than the fractal dimension. For consistency, we use GRASSBERGER'S [13] measure of entropy $K_{2}$. $K_{2, d}(c)=\left(1 / r j \ln \left(C_{d}(c) / C_{d+1}(x)\right)\right.$ and $K_{2}$ is the limiting value for large $d$ and small c. For suffictentiy smali this gives $\ln \left(C_{d}\right)-\ln \left(C_{d+1}\right)=T_{2}$. As Grassberger has descriled, this produces an offset at smallc on the usual $\log \left(C_{d}(c)\right)$ vs $\log (c)$ plot (Fig. 8). Since all the curves intersect at $c=1$ this distorts the siopes closi: to the origin, and for large enough, the scaling region is driven below the ilmits of resolution.

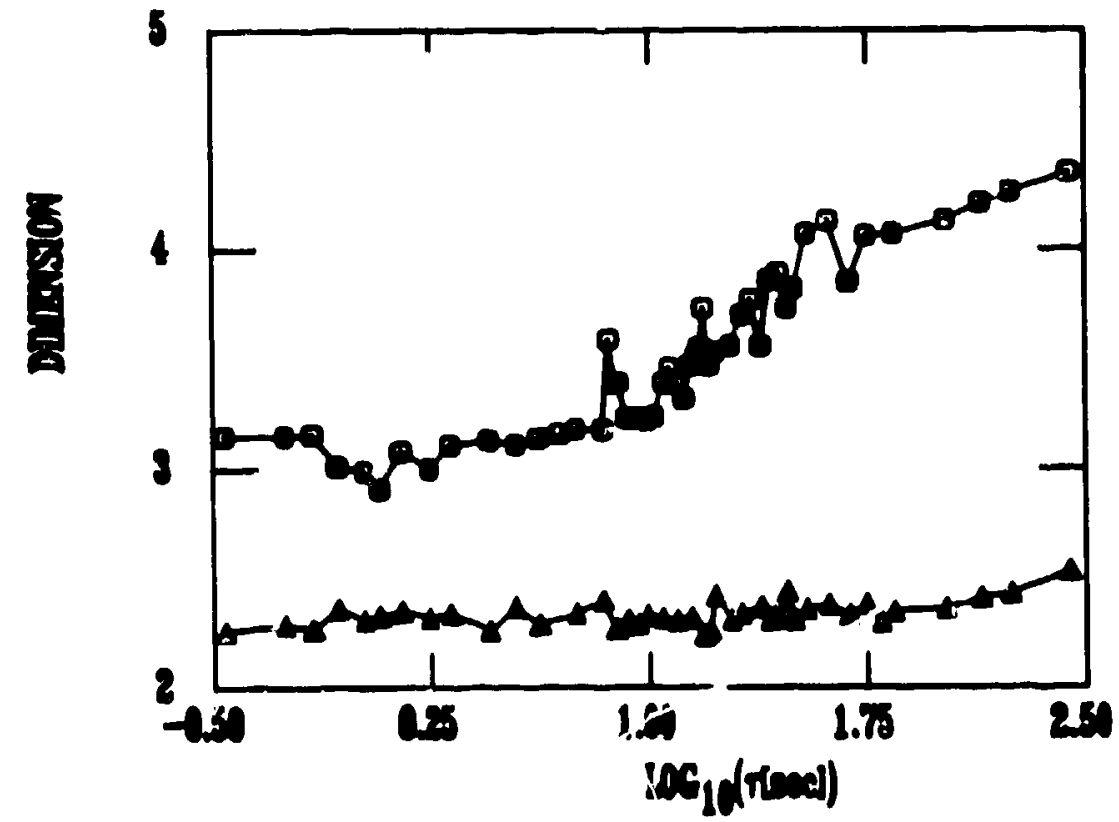

519. 7. Variation of fractal dimension with delay f for an embedding dimension of ftve and $K_{r e f}=200$. Limes are guldes to the eye for quasiperiodic data (a) and chaotic datd (0)

Extraction of the dimerision irom three different data sets is 1llustrated in fig. 8 a long with their assoclated Poincore sections. The scaling regtons chosell for the $\log _{10}(C(c))$ vs. $\log _{10}(c)$ plots are indicated. The Grassberger aluorithm with Href = 500 and max norm were used. Cases a) and b) correspond to the prevlous quast-pertodic and rhaotic data sets: c) is a particularly difficult instance. The ablitty of the dimensicn algorlthms to distingulsh lockea, quasiperlodic ant cheotic states was comparable to one's own ablilty based on origine! inspection of pier spectral density plots and Polncare sections for the three different kinds of states. 



Fig. 8. The left-hand column shows plots of $\log 10 C(c)$ vs. $\log 0$ (c) for three data sets. We evaluated the Grassberger dimenston by fitting a stralght itne to the lndicated portions of the plots. On the right are the corresponding Poincare sections. These sections were produced in the same menner as Flg. 4. a) simple quastperiodic data. $=3-7 ;$ b) Chaotic data, $d=3-10$; c) An example of data set where the ofmenston is difficult to determine, $d=5-7$

In Fig. 9 we show the behovior of dimension with increasing $R / R_{C}$ calculated just as for fig. 8. One can see an average trend of increasing dimenston, as well as rapld 
variations produced by periodic windows. This is similar to behavior found in the supercritical circle map [14]. We intend to explore the scaling of dimension with $R / R_{c}$ and the perfodic window structure in the supercritical regine in some future study.

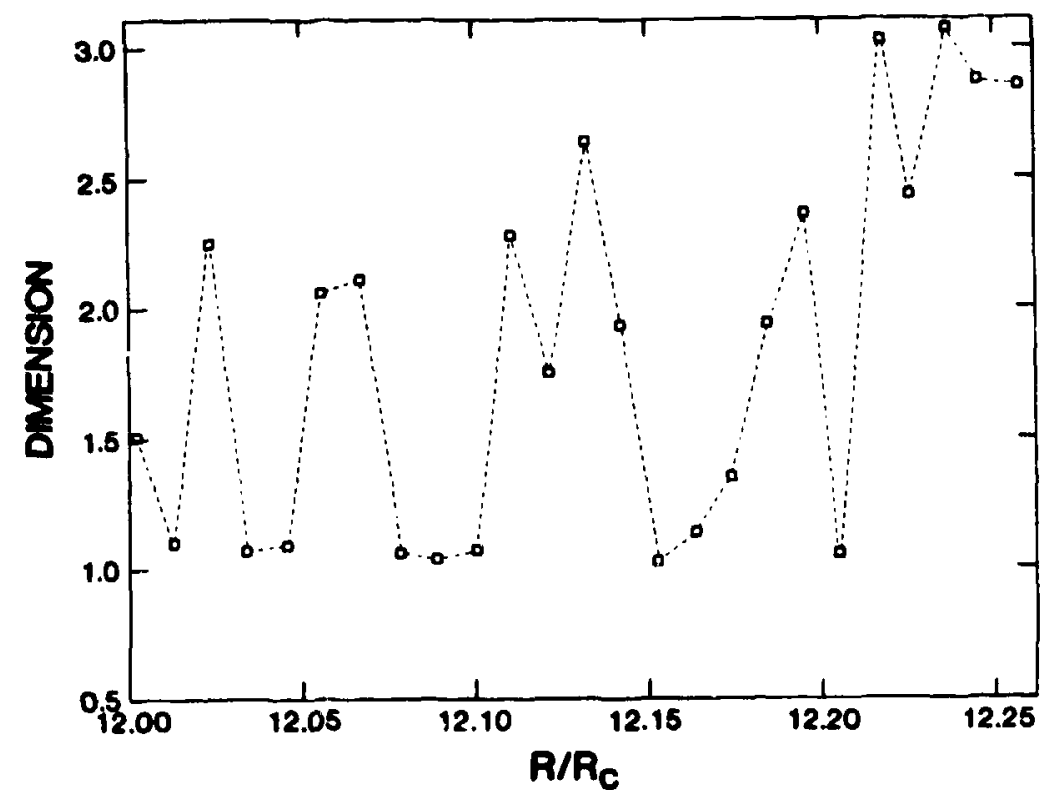

Fig. 9. The Grassberger dimension is shown as a function of normalized Rayleigh riumber

In our entropy calculations we benefited from a paper by CAPUTO and ATTEN [15]. This prompted us to try the algorithm put forth by SRASSBERGER [13]; we prefer it over TERMONIA's method [16]. Grassberger's algorithm calculates a quantity $K_{2}$ which is a lower bound on the Kolomogorov entropy. We used the maximum norm in our calculations as suggested in refs. [9] and [13]. In Fig. 10 we show plots of $K_{2, d}(c)$ for the same

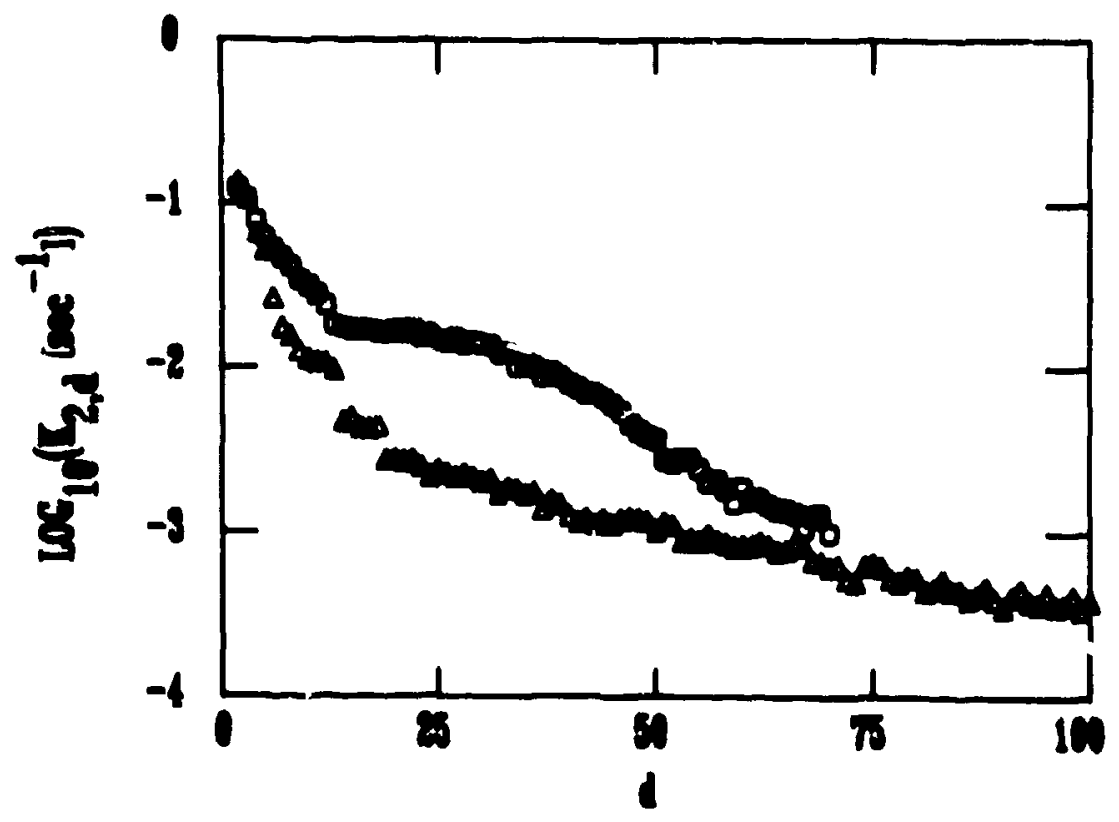

F19. 10. $K_{2, d}(c)$ is plotted as funcition of the embeddiny dimension d for quastperiodic (a) and chaotic (0) data sets. Note the plateau in the chaotic case 
quasiperiodic and chaotic data as Figs. 6-8, with Mref $=3000$. The chaotic data gives a conspicuous plateau reyion and then falls of $f$ as the amount of datc becomes insufficlent, whereas the quasiperfodic data decreases smoothly. A value of $c=0.15$ was used (with the total excursion of the time series nomalized to unity). Figure 11 shows the behavior of $K_{2}$ with varying $R / R_{c}$. Three types of points are used. The open and closed circles denote values obtained at $d=100,1=7 \mathrm{sec}$. Nref $=300$, and $c=0.15$ (averaged over $90 \leq d \leq 100$ ). In some cases the data secmed to indicate a sma 11 positive entropy but no piateau was found, and these are the open circles. The $x$ points are value; obtained by fitting to a plateau region. An attempt to check the scaling with, showed that the entropy tended to increase somewhat as was reduced. This is probalily due to the fact that as $T$ is decreased one examines more phase space points per unit time, which has an effect similar to decreasing $c$. We are probably underestimating the entropy noticably for the $x$ cases due to the relatively large value of $c$.

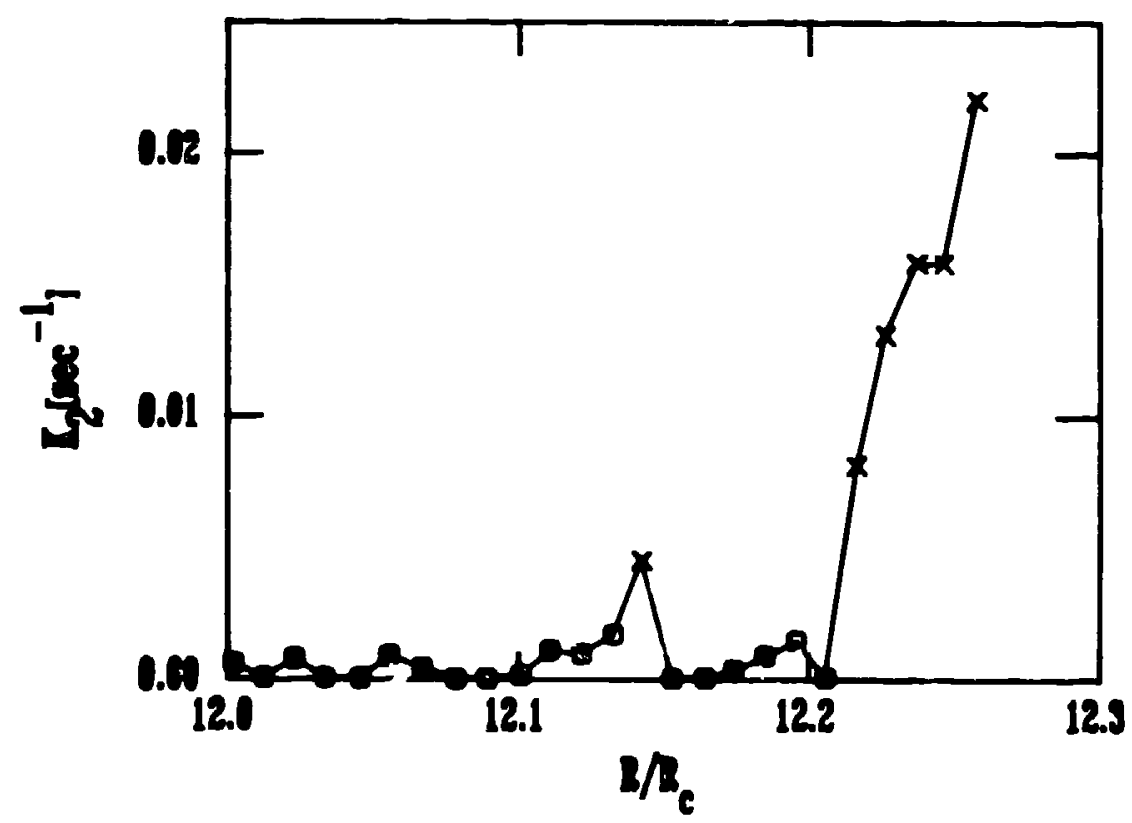

Fig. 11. $K_{2}$ versus normalized Rayleigh number

We are pleased to acknowledge valuable conversations witr. D. Farmer and $E$. Jen.

\section{References}

1. B. Malraison, P. Atten, P. Berze, and M. Dubots: J. Physique $L-897$ (1983)

2. M. Giglio, S. Musazzi, and U. Perini: Phys. Rev. Lett. 53, 2402 (1984)

3. A. Braridstater, J. Swift, H. I. Swinney. A. Wolf, J. D. Fammer. E. Jen, and P. J. Crutchfield: Phys. Rev. Lett. 51 , 1442 (1983)

4. J. Guckenheimer and G. Buzyna: Phys Rev. Lett. 51.1438 (1983)

5. J. P. Eckmann and D. Ruelle: Rev. Mod. Phys. 57. 617 (1985)

6. A. Fetter: Phys. Rev. B26. 1164 and 1174 (1982)

7. Y. Maeno, M. Haucke, R. Ecke, and J. C. Wheatley: 2. Low Tomp. Phys. 59, 305 (1985)

8. Y. Maeno. M Haucke, and J. C. Wheatley: Phys. Rev. Lett. 54, 345 (1985)

9. R. Ecke. H. Haucke, and J. Whatley: to be published in Proceedings of eperspectives on Nonlinear Oynamics" workshop (1985); H. Haucke, R. Ecke, and J. wheatley: to be pwollished

10. M. H. Packard. J. P. Crutchfteld, J. D. Famer, and R. S. Shaw: Phys. Rev. Lett. 45, $712(1980)$

11. P. Grassberger and I. Procaccla: Phys. Rev. Lett. 50, 346 (1983) 
12. Y. Termonia and 2. Alexandrowicz: Phys. Rev. Lett. 51, 1265 (1983)

13. P. Grassberger and I. Prozaccia: Phys. Rev. A28, 2591 (1983)

14. M. Jensen and I Procaccla: Phys. Rev. A32, 1225 (1985)

15. J. G. Caputo and P. Atten: preprint

16. Y. Termonia: Phys. Rev. A29. 1612 (1984) 